Europe's Journal of Psychology, 6(3), pp. 9-33

www.ejop.org

\title{
A Behav ioral Genetic Study of Relationships Between Humor Styles And The Six HEXACO Personality Factors
}

Livia Veselka

Department of Psychology, University of Western Ontario, London, Canada

Julie A. Schermer

Management and Organizational Studies, University of Western Ontario, London,

Canada

Rod A. Martin

Department of Psychology, University of Western Ontario, London, Canada

Lynn F. Cherkas

Twin Rese arch and Genetic Epidemiology Unit, King's College London, UK

Tim D. Spector

Twin Rese arch and Genetic Epidemiology Unit, King's College London, UK

Philip A. Vernon

Department of Psychology, University of Western Ontario, London, Canada

\section{Abstract}

In this study, four humor styles (affiliative, self-enhancing, aggressive, self-defeating) were assessed in conjunction with a measure of the HEXACO model of personality, in order to gain greater insight into the etiology of these humor styles, and to situate them better in the framework of human personality. Participants were 664 monozygotic twin pairs and 522 dizygotic twin pairs from the United Kingdom who completed the Humor Styles Questionnaire and the HEXACO Personality Inventory. Univariate behavioral genetic analyses of the HEXACO revealed that individual differences in all of its dimensions were entirely attributable to additive genetic and non-shared environmental factors. Significant phenotypic correlations were found between many of the HEXACO factors 
and the four humor styles, and bivariate behavioral genetic analyses revealed that these correlations were themselves accounted for entirely by correlated genetic and correlated non-shared environmental factors. Our study adds to the literature validating humor as a personality construct and assessing its relations to psychological well-being.

Key words: Humor Styles, HEXACO model of personality, behavioral genetics, individual differences.

Over the past several years, there has been a dramatic shift in the way psychologists perceive humor. No longer viewed as a one-dimensional construct with consistently beneficial effects on physical and psychosocial well-being (e.g., Lefcourt, 2001; Martin, 2001), humor is now defined by a complex collection of traits that relate to both beneficial and deleterious outcomes (Martin, Puhlik-Doris, Larsen, Grey, \& Weir, 2003). Most recently, the notion of humor styles-different ways of expressing and using humor-has attracted a substantial empirical following (Martin et al., 2003). While a considerable portion of the emerging research has focused on better understanding these styles (e.g., Chen \& Martin, 2007; Frewen, Brinker, Martin, \& Dozois, 2008), very little is centered upon situating these styles within various frameworks of human personality, and understanding their etiology in the context of these frameworks. Although some research is available that examines humor styles in conjunction with the Big Five model-the conventional structure of human personality (e.g., Vernon, Martin, Schermer, \& Mackie, 2008b)—studies assessing different and more elaborate structures of personality in relation to humor do not exist.

Given that there is still a lack of consensus as to the true structure of personality (Lee \& Ashton, 2004), and a continuing debate as to the number of higher-order dimensions that are needed to account for the variance in human personality (e.g., Veselka, Schermer, Petrides, \& Vernon, 2009, but see also Ashton, Lee, Goldberg, and de Vries, 2009), this restricted focus on the Big Five model in personality research is not justified. With this in mind, the present study focuses on humor styles in relation to the HEXACO model-an alternative structure of personality comprising six rather than five higher-order dimensions (Ashton \& Lee, 2001). In addition to reporting the first behavioral genetic investigation of the HEXACO model, our study assesses the phenotypic correlations between the four humor styles and the six dimensions of this model. Further, by using data obtained from samples of twins, the study explores the extent to which obtained phenotypic correlations are attributable to correlated genetic and/or correlated environmental factors. 
Development And Behavioral Genetic Investigation Of The HEXACO Model

Throughout most of the 20th century, little consensus existed regarding the structure of human personality (Lee \& Ashton, 2004). Several models were put forth, offering varying numbers of higher-order dimensions (e.g., Cattell, 1946; Eysenck, 1947; Wiggins, 1979), but with the exception of Eysenck's P-E-N model, none gained an especially strong following. By the 1980s, however, the research community began to embrace the idea that variation in human personality was attributable to five broad, roughly orthogonal dimensions (e.g., Goldberg, 1990; Saucier \& Goldberg, 1996). Collectively named the "Big Five" (Goldberg, 1990), these factors comprised Extraversion, Agreeableness, Conscientiousness, Emotional Stability, and Intellect/Imagination. Costa \& McCrae (1985) incorporated these five dimensions into their personality questionnaire research, which led them to propose the existence of a Five Factor Model of personality-a model very similar, though not identic al, to the Big Five.

Since the emergence of five-factor models of personality, lexical investigations carried out in a number of different languages have pointed to the potential existence of more elaborate personality models. Specifically, studies conducted in German (Angleitner \& Ostendorf, 1989), Dutch (De Raad, 1992), Korean (Hahn, Lee, \& Ashton, 1999), and French (Boies, Lee, Ashton, Pascal, \& Nicol, 2001) have all noted the existence of a sixth factor of personality in addition to the conventional five-one that touches upon sincerity and modesty. Moreover, studies carried out in Hungarian and Italian have confirmed a five-factor solution of human personality structure, but have defined the fifth factor as reflecting integrity and trustworthiness rather than the conventional intellect/imagination (e.g., De Raad \& Szirmak, 1994; Di Blas \& Forzi, 1998). Taking these results into account, Ashton and Lee (2001) proposed the HEXACO model of personality, which is composed of six distinct dimensions. Five of these dimensions are conceptually similar to those of the Big Five (Extraversion, Agreeableness, Conscientiousness, Emotionality, and Openness to Experience). The sixth factor is labeled Honesty-Humility, and is defined by characteristics such as modesty, fairness, sincerity, and lack of greed (Lee \& Ashton, 2004).

Although behavioral genetic analyses of the HEXACO model have not yet been undertaken, the Big Five factors of personality have been investigated using this approach, the results of which shed some light on the potential etiology of at least some of the HEXACO dimensions. Across the great majority of the av ailable studies, there is a consensus that individual differences in the Big Five dimensions are attributable primarily to genetic and non-shared environmental factors (i.e., things 
which one twin experiences but which their co-twin does not experience; for example, having different friends or being assigned to different teachers at school), with negligible contribution from the shared environment (i.e., things which both twins have in common; such as growing up in the same homes or going on vacations together with their parents) (e.g., Jang, Livesley, \& Vernon, 1996; Jang, McCrae, Angleitner, Riemann, \& Livesley, 1998; Loehlin, 1992; Riemann, Angleitner, \& Strelau, 1997). Further research by Loehlin, McCrae, Costa, and John (1998) has shown that the Big Five dimensions are all approximately equally heritable, and that these heritabilities do not differ significantly across sexes. Most recently, Johnson, Vernon, and Feiler (2008) reviewed every behavioral genetic study of the Big Five and related personality traits that had ever been conducted: they found 145 such studies, carried out between 1955 and 2007, and their review confirmed that additive genetic and non-shared environmental factors accounted for the majority of the variance in these traits. Their review, and the other investigations referred to above, however, did not include the sixth HEXACO factor of Honesty-Humility, which does not have a Big Five analogue, and therefore information on the genetic and/or environmental etiology of this factor is currently not av ailable.

Humor Styles And Their Personality Correlates

Humor styles were first introduced in early psychological research, where it was observed that certain uses of humor (e.g., perspective-taking, affiliative) were linked to positive psychological functioning, whereas other forms of humor (e.g., sarcastic, disparaging) were associated with more negative outcomes (e.g., Allport, 1961; Freud, 1928; Maslow, 1954). However, it was Martin et al. (2003) who formally proposed the existence of distinct humor styles-two positive and two negativeafter noting that previous empirical studies had found only weak associations between measures of humor and mental health variables (e.g., Kuiper \& Martin, 1998; Thorson, Powell, Sarmany-Schuller, \& Hampes, 1997), and inconsistent relations between humor and physical health constructs (Martin, 2001). Specifically, Martin et al. (2003) proposed the existence of affiliative, self-enhancing, aggressive, and selfdefeating styles of humor.

Affiliative humor is a non-hostile form of humor that is intended to amuse others as a way of facilitating relationships. Self-enhancing humor sees individuals finding amusement in life's hardships and incongruities, allowing them to maintain a humorous outlook even when faced with adversity. Aggressive humor is a form of disparaging humor that entails sarcasm and put-downs, and which can be used to manipulate others. Finally, self-defeating humor involves saying funny things at one's 
own expense in order to gain approval, and laughing along with others when one is being ridiculed. Only the affiliative and self-enhancing humor styles have been linked positively to psychological well-being, whereas aggressive and self-defeating humor styles tend to be negatively associated with well-being and relationship satisfaction (e.g., Kazarian \& Martin, 2006; Martin, 2007; Martin et al., 2003).

In developing the theory behind these humor styles, Martin et al. (2003) also assessed associations between the styles and the Big Five factors of personality. The authors found that the affiliative and self-enhancing humor styles were positively associated with Extraversion and Openness, with self-enhancing humor further correlating positively with Agreeableness. Additionally, significant negative correlations were noted between the aggressive and self-defeating humor styles and the factors of Agreeableness and Conscientiousness. Finally, significant relations between Neuroticism and some of the humor styles were observed, with the self-enhancing humor styles correlating negatively with this dimension, and the aggressive and selfdefeating styles correlating positively. These findings were largely replicated by Vernon, Martin, Schermer, and Mackie (2008).

Given the relatively novel status of the HEXACO model, it has not yet been assessed in terms of its relations to the humor styles. While the existing research examining the correlations between the Big Five dimensions and the four styles of humor does shed some light on the manner in which five of the six HEXACO factors would be expected to relate to the humor styles, this research does not provide any clues about the HEXACO factor of Honesty-Humility. Previous work that has noted a positive association between fairness and well-being (e.g., Sparr \& Sonnentag, 2008; Tortia, 2008) suggests that a positive relation between Honesty-Humility and the two positive humor styles will be found, because the latter have also been linked to wellbeing (e.g., Kazarian \& Martin, 2006; Martin et al., 2003). It might also imply negative correlations between this HEXACO dimension and the two negative humor styles, which tend to be negatively associated with mental health (e.g., Martin et al., 2003). These suggestions are at this point quite speculative, however, and require empirical inquiry.

Previous Behavioral Genetic Analyses Of Humor Styles

Early research on the behavioral genetic origins of variation in humor focused on humor appreciation, which assessed the extent to which participants perceived target material as being funny (Vernon, Martin, Schermer, Cherkas, \& Spector, 2008a). Results from these studies indicated that individual differences in humor 
appreciation were primarily attributable to shared and non-shared environmental factors (e.g., Cherkas, Hochberg, MacGregor, Snieder, \& Spector, 2000; Nias \& Wilson, 1977; Wilson, Rust, \& Kasriel, 1977). Later assessments of humor, however, noted that the construct of humor appreciation, though legitimate, was not related to one's ability to produce or to engage in humor, and was therefore not a valid representation of sense of humor or humor style (Köhler \& Ruch, 1996). As such, subsequent behavioral genetic research on humor shifted to assess individual differences in sense of humor, which represents the extent to which individuals notice and enjoy humor, maintain a cheerful outlook, and laugh and smile frequently (e.g., Martin, 1996). Findings from these studies suggested that variation in sense of humor is partly heritable (Loehlin \& Nichols, 1976), and attributable to a combination of genetic and non-shared environmental factors (e.g., Manke, 1998).

Most recently, behavioral genetic research on humor has begun to focus on humor styles. Vernon et al. (2008a) carried out the seminal study assessing the potential etiology of humor styles, and found that individual differences in all of the styles were accounted for by genetic, shared, and non-shared environmental factors. Specifically, they observed that the affiliative and self-enhancing humor styles were primarily influenced by genetic and non-shared environmental effects, with only a negligible contribution from shared environmental factors. Variation in the aggressive and self-defeating styles, on the other hand, was mainly attributable to shared and non-shared environmental factors. The researchers further carried out a bivariate behavioral genetic investigation to assess the extent to which phenotypic correlations between the four humor styles and the Big Five factors of personality were attributable to common genetic and/or environmental factors. Results revealed that the obtained phenotypic correlations were entirely accounted for by correlated genetic and correlated unique environmental factors. No significant shared environmental correlations were noted between the variables. These results suggest that both the humor styles and the Big Five dimensions share some of the same genetic and non-shared environmental determinants.

Biv ariate behavioral genetic studies that employ humor style variables have not yet been carried out in conjunction with personality structures other than the Big Five, meaning that shared etiological factors underlying the HEXACO dimensions and the four humor styles have not yet been assessed. The work of Vernon et al. (2008a) provides a good basis for this type of research, given that five factors of the HEXACO model are very similar to the Big Five, and may therefore yield similar results. The Honesty-Humility factor, however, has not been explored in relation to humor styles, and will therefore make a novel contribution to this area of research. 


\section{Present Study}

The purpose of the present study was to gain a greater understanding of humor styles by examining them in relation to an alternative model of personality-that of the HEXACO. In this study, humor styles were measured using the Humor Styles Questionnaire (HSQ; Martin et al., 2003) and the HEXACO factors were assessed using the short form HEXACO-60 (Ashton \& Lee, 2009). Univariate behavioral genetic analyses were first employed to investigate the extent to which individual differences in the HEXACO factors can be accounted for by genetic and/or environmental factors-findings that are important for better understanding results at the bivariate level (Plomin, 1986). Phenotypic correlations between the four humor styles and the six HEXACO dimensions were then computed to determine the relations between these sets of constructs, and to situate the humor styles into an alternative personality model other than the Big Five. Finally, bivariate behavioral genetic analyses were carried out to assess the extent to which any obtained phenotypic correlations are attributable to common genetic and/or environmental factors. These analyses will provide a deeper glimpse into the potential etiology of humor styles in relation to personality structure dimensions.

In the univariate behavioral genetic assessment of the HEXACO model, it was predicted that variation in all six dimensions would be accounted for by genetic and non-shared environmental factors. As noted above, previous studies of the Big Five factors of personality, which are roughly analogous to five of the six HEXACO factors, exhibit this pattern of results. Although no previous etiological work has been done on the variables characterizing the sixth factor of Honesty-Humility, or on the dimension itself, it was expected that it would behave as most personality variables do-showing primarily genetic and non-shared environmental effects (Johnson et al., 2008).

In terms of phenotypic correlations, it was predicted that the positive and negative styles of humor would exhibit different patterns of associations with the HEXACO dimensions. Specifically, based on previous findings with the Big Five model (e.g., Martin et al., 2003; Vernon et al., 2008b), it was expected that affiliative and selfenhancing humor styles would correlate positively with the HEXACO factors of Extraversion and Openness. It was also expected that aggressive and self-defeating humor would correlate negatively with Agreeableness and Conscientiousness, and positively with Emotionality-the HEXACO analogue to the Big Five's Neuroticism. Finally, an additional positive correlation was predicted between Agreeableness and self-enhancing humor. With regard to the Honesty-Humility dimension, it is 
plausible that this might correlate positively with the two positive humor styles, given that these humor styles as well as the Honesty-Humility factor all show associations with psychosocial well-being (e.g., Martin et al., 2003). By the same token, it was expected that the two negative humor styles would show negative correlations with Honesty-Humility, because they tend to be negatively associated with well-being (e.g., Kazarian \& Martin, 2006).

Finally, it was predicted that the bivariate behavioral genetic analyses would show that the phenotypic correlations between the humor styles and the HEXACO dimensions would be accounted for by correlated genetic and correlated nonshared environmental factors. This prediction is especially salient for the HEXACO dimensions that are similar to those of the Big Five, given that the correlations between these Big Five dimensions and the four humor styles have previously been shown to be attributable to genetic and unique environmental effects. Because there is presently no large body of research dealing with the personality correlates of the Honesty-Humility dimension of the HEXACO, predicting its behavior under bivariate behavioral genetic investigation with the four humor styles is less straightforward. It was, however, suggested that any observed correlations between the humor styles and Honesty-Humility would also be accounted for by correlated genetic and non-shared environmental factors, based on the pattern of results obtained with other higher-order personality dimensions (e.g., Vernon et al., 2008a).

\section{Method}

Participants

Participants in the present study were 1,186 pairs of twins: 664 monozygotic (MZ) twin pairs (604 female pairs and 60 male pairs) and 522 dizygotic (DZ) twin pairs (482 female pairs and 40 male pairs). Although there are many more females than males in our samples, this is not uncommon in research with twins (Lykken, McGue, \& Tellegen, 1987) but is particularly exaggerated in our sample because the original focus of research with these twins was the genetics of osteoporosis and osteoarthritis: conditions which are much more common among females. Twins ranged in age from 18 to 92 years $(M=56.4, S D=13.2)$, and were participants in ongoing studies conducted by the Department of Twin Research and Genetic Epidemiology (DTR) at King's College London in England. This department mails out questionnaires to approximately 9,000 individual twins each year. The zygosity of participating twins has been established by means of genome scans (100\% accurate), DNA tests $199.5 \%$ accurate), or by responses to the "Peas in a pod" zygosity questionnaire $195 \%$ 
accurate). Twins taking part are not compensated for their participation.

Materials

Humor Styles Questionnaire (HSQ). Individual differences in four humor styles (affiliative, self-enhancing, aggressive, and self-defeating) were assessed using the 32-item HSQ (Martin et al., 2003). Each item of the HSQ presents a self-reflective statement pertaining to humor. Participants indic ate the extent to which they agree with each statement using a 7-point Likert Scale (where $1=$ totally disagree and $7=$ totally agree). Example items include: "I enjoy making people laugh" (affiliative); "If I'm by myself and I'm feeling unhappy, I make an effort to think of something funny to cheer myself up" (self-enhancing); "If I don't like someone, I often use humor or teasing to put them down" (aggressive); and "Letting others laugh at me is my way of keeping my friends and family in good spirits" (self-defeating). Reliabilities of the scales are .81 for self-enhancing humor, 80 for affiliative and self-defeating humor, and .77 for aggressive humor.

HEXACO Personality Inventory. Participants also completed the 60-item HEXACO Personality Inventory (HEXACO-60; Ashton \& Lee, 2009), which assesses individual differences in six personality dimensions-conscientiousness, extraversion, agreeableness, openness to experience, emotionality, and honesty-humility. Participants responded to self-reflective statements on this questionnaire via a 5point Likert scale (where 1 = strongly disagree and 5 = strongly agree). Internal consistency reliabilities for the scales have been reported to range between .77 and .80 in a sample of college students and between .73 and .80 in a community sample (Ashton \& Lee, 2009).

Procedure

In November 2008, approximately 9000 individual twins were mailed a questionnaire which included the HEXACO-60 as well as additional questions that are not pertinent to the present study. Approximately 5000 individual twins (56\%) returned the completed questionnaires and, of these, a total of 3012 were complete same-sex pairs (837 MZ pairs and $669 \mathrm{DZ}$ pairs). Two years earlier, the questionnaire mail-out included the HSQ, and $664 \mathrm{MZ}$ and $522 \mathrm{DZ}$ twin pairs had completed this as well as the HEXACO. Twins completed the questionnaires at their own time in their homes, and returned them to the DTR. 
Analyses

Even though the majority of the participating twins completed the questionnaires in full, there were rare instances in which an item was left blank. In these cases, the missing information was replaced with the average of the item's Likert scale. Subsequently, the items of the HSQ were reduced to four scores reflecting the four humor styles being assessed. Similarly, the items of the HEXACO-60 were converted to six unique scores corresponding to the six dimensions of the HEXACO model of personality. Prior to analysis, all data were corrected for age and sex via the regression approach proposed by McGue and Bouchard (1984). This controls for any age or sex differences which might exist (see below) and is particularly important given the much greater number of females than males in our sample.

When conducting univariate behavioral genetic analyses, members of each twin pair were randomly designated as "Twin 1" or "Twin 2" and between-twin correlations were then calculated separately for MZs and DZs. Structural equation model-fitting was then carried out using the software package Mx (Neale, Boker, Xie, \& Maes, 2006) to estimate the extent to which individual differences can be attributed to additive genetic (A), shared environmental (C), and non-shared environmental factors (E). Although it is possible to fit reduced models to data (e.g., $A E, C E)$, we did not do so in the present analysis due to the recommendations of Sullivan and Eaves (2002). These researchers have suggested that such reduced models yield oversimplified rather than more parsimonious results, whereas full ACE models provide accurate estimates for discrete traits.

Biv ariate BG analyses were also performed using Mx. These analyses estimate the extent to which observed phenotypic correlations between variables are attributable to common genetic and/or common environmental influences by examining the cross-correlations within twin-pairs (i.e., the correlation between one twin's score on one variable with their co-twin's score on another variable) using the method of Cholesky or triangular factor analysis (Neale \& Cardon, 1992). In conducting these analyses, a full ACE model was tested as well as reduced AE and CE models: the model with the lowest chi-square value and lowest AIC value is chosen as the best fitting model. For each of the correlations reported in Table 2 below, an AE model was found to have the best fit, resulting in estimates of genetic (rg) and non-shared environmental (re) correlations. 


\section{Results}

Given the large size of our samples, not surprisingly significant sex differences were found on most of the variables. In fact, of the six HEXACO and the four HSQ variables, significant differences existed on all except conscientiousness and openness. Females obtained significantly higher scores on honesty-humility, emotionality, and agreeableness (all 2-tailed $\mathrm{p}<.0001$ ); males scored significantly higher than females on extraversion ( $\mathrm{p}<.05$, 2-tailed) and on all four HSQ humor styles (all 2-tailed $\mathrm{p}<.05$ ). These findings are not atypical, particularly for emotionality, honesty, and aggressive humor (e.g., Ashton \& Lee, 2009; Chen \& Martin, 2007; Kazarian \& Martin, 2006), although it also bears noting that the actual mean differences between males and females were quite small. We also found significant correlations between age and all HEXACO and HSQ variables except openness, although these were again quite small, ranging from .04 for age and selfenhancing humor to -.21 for age and affiliative humor. Though small, these significant age and sex effects nonetheless need to be (and were) controlled for before conducting the analyses that follow.

Twin correlations and parameter estimates derived from univariate behavior genetic analyses of the six HEXACO dimensions are presented in Table 1. For all of the dimensions, MZ correlations were substantially larger than DZ correlations, implying the existence of genetic effects. Model-fitting results clarified these effects by revealing that individual differences in the higher-order HEXACO factors can be accounted for entirely by genetic and non-shared environmental effects. Genetic effects were particularly strong for the HEXACO dimension of Openness to Experience (.59) while Conscientiousness exhibited the lowest contribution from genetic factors (.32). This is the first report on the heritability of the HEXACO dimensions and it is of interest that Honesty- the dimension unique to the HEXACO model- shows a similar degree of genetic influence (.35) as several of the other more traditional dimensions.

Table 1

Twin Correlations and Parameter Estimates for the HEXACO Dimensions

\begin{tabular}{|c|c|c|c|c|c|}
\hline \multirow[t]{2}{*}{ Variables } & \multicolumn{2}{|c|}{ Correlations } & \multicolumn{3}{|c|}{ Parameter estimates $(95 \% \mathrm{Cl})$} \\
\hline & $\overline{M Z}$ & $\overline{\mathrm{DZ}}$ & $a^{2}$ & $c^{2}$ & $e^{2}$ \\
\hline \multirow[t]{2}{*}{ Honesty } & .36 & .14 & $.35(.22$ to & .001 .00 to & $.65(.60$ to .71$)$ \\
\hline & & & $.40)$ & $.11)$ & \\
\hline Emotionality & .49 & .23 & .48 (.30 to & .001 .00 to & $.52(.48$ to .58$)$ \\
\hline
\end{tabular}




\section{$.52)$}

\begin{tabular}{|c|c|c|c|c|c|}
\hline Extraversion & .48 & .14 & $\begin{array}{l}.45 \text { (.36 to } \\
.50)\end{array}$ & $\begin{array}{l}.00(.00 \text { to } \\
.07)\end{array}$ & .55 (.50 to .60) \\
\hline Agreeableness & .40 & .12 & $\begin{array}{l}.37 \text { (.28 to } \\
.42)\end{array}$ & $\begin{array}{l}.00(.00 \text { to } \\
.07)\end{array}$ & .63 (.58 to .68) \\
\hline $\begin{array}{l}\text { Conscientiousn } \\
\text { ess }\end{array}$ & .33 & .16 & $\begin{array}{l}.32(.14 \text { to } \\
.38)\end{array}$ & $\begin{array}{l}.00(.00 \text { to } \\
.16)\end{array}$ & .68 (.62 to .74) \\
\hline Openness & .59 & .28 & $\begin{array}{l}.59 \text { (.48 to } \\
.63)\end{array}$ & $\begin{array}{l}.00(.00 \text { to } \\
.10)\end{array}$ & $.41(.37$ to .46$)$ \\
\hline
\end{tabular}

Note. $a^{2}=$ additive genetic effects; $c^{2}=$ shared environmental effects; $e^{2}=$ nonshared environmental effects; $\mathrm{Cl}=$ confidence interval. All effects whose confidence intervals do not include zero are significant at the .05 level.

The results of univariate genetic analyses of the HSQ within this sample have been reported previously (Vernon, Martin, Schermer, Cherkas, \& Spector, 2008). In brief, in this UK sample of twins individual differences in all four humor styles were found to be attributable to additive genetic and non-shared environmental factors, with heritability estimates ranging between .34 (self-defeating humor) and .49 (affiliative humor).

Phenotypic correlations (rp) between the HSQ and the HEXACO-60 are shown in Table 2. From these correlations, it is evident that the affiliative and self-enhancing humor styles are positively associated with HEXACO's Extraversion and Openness to Experience and to a lesser extent with Conscientiousness. Both positiv e humor styles are also negatively correlated with the model's Emotionality dimension. Affiliative humor also shows a small but significant negative correlation with the HonestyHumility factor, while self-enhancing humor correlates positiv ely with Agreeableness. As would be expected, aggressive and self-defeating humor styles are negatively related to HEXACO's Honesty-Humility, Agreeableness, and Conscientiousness factors. Self-defeating humor shows a positive correlation with the Emotionality dimension, whereas aggressive humor has a small but significant negative 
correlation. Self-defeating humor also has a small but significant negative correlation with Extraversion.

Table 2

Phenotypic (rp, ) Genetic (rg) and Environmental (re) Correlations with Confidence Interval Values between the HEXACO Dimensions and the Humor Styles Measured by the $H S Q$

\begin{tabular}{|c|c|c|c|c|}
\hline & \multicolumn{4}{|c|}{ HSQ Scales } \\
\hline & Affiliative & Self-enhancing & Aggressive & Self-defeating \\
\hline \multirow[t]{3}{*}{$\mathrm{H}$} & $\mathrm{Rp}=-.06^{*}$ & $r p=.01$ & $r p=-.33^{*}$ & $r p=-.16^{*}$ \\
\hline & $\begin{array}{l}r g=-.10(-.23 \text { to } \\
.02)\end{array}$ & $\begin{array}{l}r g=-.03(-.17 \text { to } \\
.11)\end{array}$ & $\begin{array}{l}r g=-.55(-.43 \text { to }- \\
.76)\end{array}$ & $\begin{array}{l}\mathrm{rg}=-.21(-.08 \text { to }- \\
.35)\end{array}$ \\
\hline & $\begin{array}{l}r e=-.03(-.10 \text { to } \\
.04)\end{array}$ & $r e=.02(-.05$ to .09$)$ & $\begin{array}{l}\text { re }=-.18(-.12 \text { to }- \\
.25)\end{array}$ & $\begin{array}{l}\text { re }=-.12(-.05 \text { to }- \\
.19)\end{array}$ \\
\hline \multirow[t]{3}{*}{ Em } & $\mathrm{rp}=-.09 *$ & $\mathrm{rp}=-.17^{*}$ & $\mathrm{rp}=-.07^{*}$ & $\mathrm{rp}=.15^{*}$ \\
\hline & $\begin{array}{l}\mathrm{rg}=-.09(-.19 \text { to } \\
.02)\end{array}$ & $\begin{array}{l}r g=-.26(-.14 \text { to }- \\
.37)\end{array}$ & $\begin{array}{l}r g=-.20(-.09 \text { to }- \\
.31)\end{array}$ & $\begin{array}{l}\mathrm{rg}=.14(.03 \text { to } \\
.25)\end{array}$ \\
\hline & $\begin{array}{l}\text { re }=-.10(-.02 \text { to } \\
.18)\end{array}$ & $\begin{array}{l}\text { re }=-.11(-.04 \text { to }- \\
.18)\end{array}$ & $\begin{array}{l}\text { re }=.03(-.04 \text { to } \\
.10)\end{array}$ & $\begin{array}{l}r e=.13(.06 \text { to } \\
.20)\end{array}$ \\
\hline \multirow[t]{5}{*}{ Ex } & $\mathrm{rp}=.42^{*}$ & $\mathrm{rp}=.39 *$ & $\mathrm{rp}=.03$ & $\mathrm{rp}=-.08^{*}$ \\
\hline & $\mathrm{rg}=.61(.53$ to & $\mathrm{rg}=.60(.50$ to .70$)$ & $\mathrm{rg}=.09(-.02$ to & $r g=-.12(-.23$ to \\
\hline & $.69)$ & $\mathrm{re}=.23(.16$ to .29$)$ & $.20)$ & $.01)$ \\
\hline & $\mathrm{re}=.26(.19$ to & & $r e=-.01(-.07$ to & $r e=-.04(-.11$ to \\
\hline & $.32)$ & & $.07)$ & $.03)$ \\
\hline \multirow[t]{5}{*}{ A } & $r p=-.01$ & $\mathrm{rp}=.19^{*}$ & $r p=-.27^{*}$ & $r p=-.06^{*}$ \\
\hline & $r g=-.10(-.22$ to & $r g=.16(.04$ to .29$)$ & $r g=-.47(-.36$ to - & $r g=-.14(-.02$ to - \\
\hline & $.01)$ & re $=.19(.12$ to .25$)$ & $.59)$ & $.27)$ \\
\hline & re $=.07(-.01$ to & & $r e=-.13(-.06$ to - & $r e=-.01(-.07$ to \\
\hline & $.14)$ & & $.20)$ & $.07)$ \\
\hline \multirow[t]{3}{*}{ C } & $\mathrm{rp}=.10^{*}$ & $\mathrm{rp}=.06^{*}$ & $\mathrm{rp}=-.16^{*}$ & $\mathrm{rp}=-.15^{*}$ \\
\hline & $\begin{array}{l}\mathrm{rg}=.25(.13 \text { to } \\
.38)\end{array}$ & $\begin{array}{l}r g=.08(-.06 \text { to } \\
.22)\end{array}$ & $\begin{array}{l}r g=-.18(-.05 \text { to }- \\
.31)\end{array}$ & $\begin{array}{l}\mathrm{rg}=-.19(-.06 \text { to }- \\
.32)\end{array}$ \\
\hline & $\begin{array}{l}r e=-.02(-.09 \text { to } \\
.05)\end{array}$ & $\begin{array}{l}\text { re }=.03(-.04 \text { to } \\
.10)\end{array}$ & $\begin{array}{l}\text { re }=-.15(-.08 \text { to }- \\
.22)\end{array}$ & $\begin{array}{l}\text { re }=-.12(-.05 \text { to }- \\
.19)\end{array}$ \\
\hline
\end{tabular}




$\begin{array}{llll}\mathrm{rp}=.20^{*} & \mathrm{rp}=.17^{*} & \mathrm{rp}=-.05 & \mathrm{rp}=.03 \\ \mathrm{rg}=.29(.21 \text { to } & \mathrm{rg}=.28(.19 \text { to } .38) & \mathrm{rg}=-.04(-.14 \text { to } & \mathrm{rg}=.11 \text { (.07 to } \\ .38) & \mathrm{re}=.06(-.01 \text { to } & .06) & .21) \\ \mathrm{re}=.09(.02 \text { to } & .14) & \mathrm{re}=-.06(-.13 \text { to } & \mathrm{re}=-.06(-.13 \text { to } \\ .16) & & .01) & .01) \\ \end{array}$

Note. $\mathrm{H}=$ Honesty-Humility. Em = Emotionality. Ex = Extraversion. $\mathrm{A}=$ Agreeableness. $\mathrm{C}=$ Conscientiousness. $\mathrm{O}=$ Openness to Experience. $\mathrm{rg}=$ genetic correlation $. \mathrm{rC}=$ shared environmental correlation. re = non-shared environmental correlation.

Numbers appearing in brackets represent the $95 \%$ confidence interval values. All correlations whose confidence intervals do not include zero are signific ant at the .05 level. $\quad * p<.01$, two-tailed.

The bivariate model-fitting results are also reported in Table 2 and reveal that the phenotypic correlations between the HEXACO and the HSQ are entirely attributable to correlated genetic (rg) and correlated non-shared environmental (re) factors. For the positive humor styles, significant genetic correlations can be seen between affiliative humor and Extraversion, Conscientiousness, and Openness to Experience, and between self-enhancing humor and Emotionality, Extraversion, Agreeableness, and Openness to Experience. For the negative humor styles, significant genetic correlations exist between aggressive humor and Honesty-Humility, Emotionality, Agreeableness, and Conscientiousness, and between self-defeating humor and all HEXACO dimensions except Extraversion. Several of the genetic correlations are quite large (e.g., .61 and .60 between extraversion and affiliative and self-enhancing humor, respectively, and -.55 between Honesty-Humility and aggressive humor), indicating substantial overlap between the genes that contribute to individual differences on each of these variables.

In terms of environmental correlations, significant non-shared environmental associations exist between affiliative humor and Extraversion and Openness to Experience, as well as between self-enhancing humor and Extraversion and Agreeableness. Significant non-shared environmental correlations can also be seen between aggressive humor and Honesty-Humility, Agreeableness, and Conscientiousness, and between self-defeating humor and Honesty-Humility, Emotionality, and Conscientiousness. The great majority of the environmental correlations were somewhat to substantially smaller than the genetic correlations between the same pairs of variables. No shared environmental correlations were found between any of the variables. 


\section{Discussion}

In addition to reporting the first behavioral genetic investigation of the HEXACO model, the present study had two main goals: to determine the associations between the four humor styles and the HEXACO dimensions, in order to situate the humor styles in a more comprehensive personality structure, and to assess the potential etiology of humor styles in the context of this structure. These goals were addressed through a correlational analysis coupled with univariate and bivariate behavioral genetic model-fitting analyses.

As predicted, individual differences in the six HEXACO dimensions were entirely attributable to genetic and non-shared environmental factors. In part, these findings replicate the results of past studies of the Big Five model (e.g., Jang et al., 1996; Johnson et al., 2008; Riemann et al., 1997), the dimensions of which are roughly analogous to five of the six HEXACO factors. These studies have reported that variance in the Big Five dimensions is largely accounted for by genetic and unique environmental factors. Beyond replicating these findings, and extending the $m$ to the HEXACO model, however, the present study also confirmed that the sixth HEXACO dimension of Honesty-Humility also behaves in the same manner as do its other dimensions. As such, the present study further validates the HEXACO model by demonstrating that all of its dimensions share a similar etiology. Moreover, it is likely that the heritabilities found in our study are lower-bound estimates because we used the short-form of the HEXACO Personality Inventory which is not as reliable as longer measures.

Many of the phenotypic correlations observed between the HEXACO dimensions and the four humor styles confirmed our predictions, and echoed the results of previous studies examining relationships between humor styles and the Big Five. These correlations are also likely to be underestimates because of the two year gap between subjects' completing the HSQ and the HEXACO-60. With regard to the prosocial humor styles (affiliative, self-enhancing), positive correlations were noted between these and HEXACO's Extraversion and Openness factors, and an additional positive correlation was observed between self-enhancing humor and HEXACO's Agreeableness dimension. Given that previous studies with the Big Five have found similar associations (e.g., Martin et al., 2003; Vernon et al., 2008b), and that the two prosocial humor styles or related measures have been linked to social intimacy (Martin et al., 2003), creativity (e.g., Oral, 2006; Wycoff \& Pryor, 2003) and trust (Hampes, 1999), which are characteristics of Extraversion, Openness, and 
Agreeableness, respectively (Lee \& Ashton, 2004), these correlations are not surprising.

With regard to the two deleterious styles of humor (aggressive and self-defeating), these were found to correlate negatively with HEXACO Agreeableness and Conscientiousness, as we had predicted. Similar findings have been reported in previous studies of humor styles and the Big Five (e.g., Martin et al., 2003; Vernon et al., 2008b). Other studies have further substantiated these findings by noting negative relations between these two humor styles and related measures, and the constructs of trust (e.g., Hampes, 1999) and perfectionism (e.g., Fry, 1995) characteristics that help to define the HEXACO factors of Agreeableness and Conscientiousness, respectively.

In addition to these predicted correlations, other associations were observed that had not been noted in previous studies of humor styles. For example, negative correlations were found between the two positive humor styles and the HEXACO dimension of Emotionality, which is an analogue to the Big Five dimension of Neuroticism. Previous studies have found this type of correlation between selfenhancing humor and Neuroticism, but have not done so with affiliative humor (e.g., Martin et al., 2003; Vernon et al., 2008b). However, given that both of these prosocial humor styles have been linked to psychological well-being (Martin et al., 2003), whereas Emotionality reflects such negative affect traits as anxiety, fearfulness, and dependence (Lee \& Ashton, 2004), the correlations we obtained hold conceptual validity.

Moreover, although we expected that both negative humor styles would correlate positively with Emotionality, given the findings of previous studies linking the Big Five's Neuroticism to aggressive and self-defeating humor, only self-defeating humor exhibited this positive relation. In our study, aggressive humor actually correlated negatively with Emotionality. It can, however, be argued that this pattern of correlations makes sense, in light of the manner in which HEXACO's Emotionality is defined. Specifically, because Emotionality is characterized by qualities such as fearfulness, anxiety, and dependence (Lee \& Ashton, 2004), it may be the case that those who employ self-defeating humor are high on the Emotionality dimension due to their insecurity (high anxiety) and excessive concern about close relationships with others (high dependence). On the other hand, those exhibiting an aggressive humor style may be unconcerned about harming the feelings of others (low anxiety), and may be motivated to push others aw ay (low dependence). 
In addition to substantially replicating many of the correlations previously noted between the Big Five and humor styles, thereby confirming the HEXACO model's validity as a higher-order personality framework, we also observed several correlations between the humor styles and HEXACO's sixth dimension of HonestyHumility. Specifically, as expected the two negative humor styles exhibited negative correlations with Honesty-Humility. Because Honesty-Humility is defined as a prosocial dimension (Lee \& Ashton, 2004), while aggressive and self-defeating humor have more socially aversive overtones (Martin et al., 2003), these obtained negative correlations are reasonable, suggesting that those who employ deleterious humor styles - particularly aggressive humor - are likely to be less sincere, less modest, less fair, and more greedy than those who do not. A small yet significant negative correlation was also found between affiliative humor and Honesty-Humility factor, which we had not predicted. This correlation may indicate that while high scorers on Honesty-Humility tend to exhibit modesty and avoid flattery, those who use affiliative humor may sometimes employ a certain amount of insincere adulation in an effort to secure friendships and, as a result, may score lower on the Honesty-Humility dimension. We acknowledge that this suggestion is speculative and that it requires further investigation.

Finally, with regard to the multivariate behavioral genetic analyses, we found that the phenotypic correlations discussed above were entirely attributable in the first instance to correlated genetic factors and secondarily to correlated non-shared environmental factors, as predicted. These results suggest that the four humor styles and the six HEXACO dimensions share many overlapping genetic and unique environmental determinants. These results also add to the existing literature by showing that all of the HEXACO dimensions, including the Honesty-Humility factor that has not been explored previously using multivariate behavioral genetic methodology, behave as other higher-order dimensions of personality have done (e.g., Vernon et al., 2008a).

To put our results into a broader context, it will be informative to look at studies of relationships between humor styles, the Big Five, and trait Emotional Intelligence (trait El) (e.g., Greven, Chamorro-Premuzic, Arteche, \& Furnham, 2008; Vernon, Villani, Schermer, Kirilovic, Martin, Petrides, et al., 2009, Vernon, Villani, Schermer, \& Petrides, 2008). The construct of trait El comprises a collection of self-perceived emotionrelated dispositions and abilities. In its global form, it is negatively associated with Neuroticism and positively associated with the other Big Five factors (Vernon et al., 2008c) - correlations which indicate its prosocial nature, while also situating it within the structure of human personality. In addition, trait El correlates positively with the 
two prosocial humor styles, and negatively with the two deleterious humor styles (e.g., Greven et al., 2008; Vernon et al., 2009). Given these links, it is possible that trait El contributes to determining why people adopt certain humor styles. Specifically, the characteristic use of positive humor styles may require high trait $\mathrm{El}$, given that individuals need to understand the emotions of others, and to manage their own emotions if they want to create friendships and overcome adversity (Vernon et al., 2009). On the other hand, those who employ negative humor styles may be lower on trait El, being emotionally unaware or emotionally self-harming in their use of humor (Vernon et al., 2009). If this is the case, then it is unsurprising that, in the present study, the positive humor styles were linked to HEXACO's Extraversion, Openness, and Agreeableness - dimensions that are associated with high trait El (Vernon et al., 2008c). This may also account for the negative correlations we found between the negative humor styles and Honesty-Humility, which is defined by constructs such as forgiv eness and fairness which in turn reflect high trait El.

Further support linking humor styles and the HEXACO model to trait El comes from research on the so-called general factor of personality (GFP) - a super-dimension that has been proposed to sit at the apex of the personality hierarchy and to subsume all personality traits in a manner similar to Spearman's $g$ in the domain of mental abilities (Ruhston, Bons, \& Hur, 2008). Using principal components analyses, Veselka, Schermer, Petrides, Cherkas, Spector, \& Vernon (2009) extracted a general factor from the six HEXACO and four trait El factors; Emotionality loaded negatively on this factor In addition, a general factor has been extracted from the Big Five factors, the four humor styles, and four factors of trait El (Rushton, Bons, Ando, Hur, Irwing, Vernon, et al., 2009). From these results, it may be that positive humor styles, trait emotional intelligence, and the HEXACO factors (including low Emotionality) have slowly evolved over time in concert with one another because they have helped to contribute to social dominance and reproductive success. It should be noted, however, that this proposition is debatable, particularly given the lack of consensus that surrounds the existence of a GFP. Recently, Ashton, Lee, Goldberg, and de Vries (2009) suggested that it is lower-order variables representing same-sign blends of multiple higher-order orthogonal dimensions that account for the noted associations between these dimensions, rather than a broad general factor. It is also possible that "halo effects" or "egoistic bias" contribute to what may be mistakenly described as a GFP (Anusic, Schimmack, Pinkus, \& Lockwood, in press).

Through this study, we have demonstrated that the HEXACO model is a valid framework structure that behaves similarly to the Big Five model when assessed in conjunction with the four humor styles. The Honesty-Humility factor of the HEXACO is 
also a justifiable addition to personality structure given its correlations with humor styles, and its etiologic al similarities to the other higher-order dimensions. In terms of the humor styles, our study has confirmed their place in personality by situating them within the HEXACO model - an alternative to the Big Five - in addition to providing greater insight into their etiology. We propose that we can account for our results by incorporating trait $\mathrm{El}$ as a mediator variable. Future investigations may wish to test the validity of including trait $\mathrm{El}$ in discussions of humor styles and other broad personality dimensions.

\section{References}

Allport, G.W. (1961). Pattern and growth in personality. New York: Holt, Rinehart \& Winston.

Angleitner, A., \& Ostendorf, F. (1989, July). Personality factors via self-and peer-ratings based on a representative sample of German trait descriptive terms. Paper presented at the First European Congress of Psychology, Amsterdam, the Netherlands.

Anusic, I., Schimmack, U., Pinkus, R., \& Lockwood, P. (in press). The nature and structure of correlations among Big Five ratings: The halo-alpha-beta model. Journal of Personality and Social Psychology.

Ashton, M. C., Lee, K. (2001). A theoretical basis for the major dimensions of personality. European Journal of Personality, 15, 327-353.

Ashton, M. C., \& Lee, K. (2009). The HEXACO-60: A short measure of the major dimensions of personality. Journal of Personality Assessment, 91, 340-345.

Ashton, M. C., Lee, K., Goldberg, L. R., \& de Vries, R. E. (2009). Higher-order factors of personality: Do they exist? Personality and Social Psychology Review, 13, 79-91.

Ashton, M. C., Lee, K., Perugini, M., Szarota, P., de Vries, R. E., Di Blas, L., et al. (2004). A sixfactor structure of personality-descriptive adjectives: Solutions from psycholexicalstudies in seven languages. Journal of Personality and Social Psychology, 86, 356-366.

Boies, K., Lee, K., Ashton, M. C., Pascal, S., \& Nicol, A. A. M. (2001). The structure of the French personality lexicon. European Journal of Personality, 15, 277-295.

Cattell, R. B. (1946). Description and measurement of personality. New York: World Book. 
Chen, G. H., \& Martin, R. A. (2007). A comparison of humor styles, coping humor, and mental health between Chinese and Canadian university students. Humor: International Journal of Humor Research, 20, 215-234.

Cherkas, L., Hochberg, F., MacGregor, A. J., Snieder, H., \& Spector, T. D. (2000). Happy families: A twin study of humour. Twin Research, 3, 17-22.

Costa, P. T., Jr. \& McCrae, R. R. (1985). The NEO personality inventory manual. Psychological Assessment Resources: Odessa, FL.

De Raad, B. (1992). The replicability of the Big Five personality dimensions in three wordclasses of the Dutch language. European Journal of Personality, 6, 15-29.

De Raad, B., \& Szirmak, Z. (1994). The search for the "Big Five" in a non-Indo-European language: The Hungarian trait structure and its relationship to the EPQ and the PTS. European Review of Applied Psychology, 44, 17-24.

Di Blas, L., \& Forzi, M. (1998). An alternative taxonomic study of personality-descriptive adjectives in the Italian language. European Journal of Personality, 12, 75-101.

Eysenck, H. J. (1947). Dimensions of personality. London: Routledge \& Kegan Paul.

Freud, S. (1928). Humour. International Journal of Psychoanalysis, 9, 1-6.

Frewen, P. A., Brinker, J., Martin, R. A., \& Dozois, D. J. A. (2008). Humor styles and personality-vulnerability to depression. Humor: International Journal of Humor Research, $21,179-195$.

Fry, P. S. (1995). Perfectionism, humor, and optimism as moderators of health outcomes and determinants of coping styles of women executives. Genetic, Social, and General Psychology Monographs, 121, 211-245.

Goldberg, L. R. (1990). An alternative "description of personality": The Big-Five factor structure. Journal of Personality and Social Psychology, 59, 1216-1229.

Greven, C., Chamorro-Premuzic, T., Arteche, A., \& Furnham, A. (2008). A hierarchical integration of dispositional determinants of general health in students: The Big Five, trait emotional intelligence, and humor styles. Personality and Individual Differences, 44, $1562-$ 1573.

Hahn, D. W., Lee, K., \& Ashton, M. C. (1999). A factor analysis of the most frequently used 
Korean personality trait adjectives. European Journal of Personality, 13, 261-282.

Hampes, W. P. (1999). The relationship between humor and trust. Humor: International Journal of Humor Research, 12, 253-259.

Jang, K. L., Livesley, W. J., \& Vernon, P. A. (1996). Heritability of the Big Five personality dimensions and their facets: A twin study. Journal of Personality, 64, 577-591.

Jang, K. L., McCrae, R. R., Angleitner, A., Riemann, R., \& Livesley, W. J. (1998). Heritability of facet-level traits in a cross-cultural twin sample: Support for a hierarchical model of personality. Journal of Personality and Social Psychology, 74, 1556-1565.

Johnson, A. M., Vernon, P. A., \& Feiler, A. R. (2008). Behavioral genetic studies of personality: An introduction and review of the results of $50+$ years of research. In $\mathrm{G}$. J. Boyle, G. Matthews, \& D. H. Saklofske (Eds.), Handbook of Personality Theory and Assessment (Vol. 1). Sage Publishers.

Holmes, J. (2007). Making humour work: Creativity on the job. Applied Linguistics, 28, 518537.

Kazarian, S. S., \& Martin, R. A. (2006). Humor styles, culture-related personality, well-being, and family adjustment among Armenians in Lebanon. Humor: International Journal ofHumor Research, 19, 405-423.

Köhler, G., \& Ruch, W. (1996). Sources of variance in current sense of humor inventories: How much substance, how much method variance? Humor: International Journal of HumorResearch, 9, 363-397.

Kuiper, N. A., \& Martin, R. A. (1998). Is sense of humor a positive personality characteristic? In W. Ruch (Ed.), The sense of humor: Explorations of apersonality characteristic (pp.159-178). New York: Mouton de Gruyter.

Lee, K., \& Ashton, M. C. (2004). Psychometric properties of the HEXACO Personality Inventory. Multivariate Behavioral Research, 39, 329-358.

Lefcourt, H.M.(2001). Humor: The psychology of living buoyantly. New York: Kluwer Academic Publishers.

Loehlin, J. C. (1992). Genes and environment in personality development. Newbury Park, CA: Sage. 
Loehlin, J. C., McCrae, R. R., Costa, P. T., \& John, O. P. (1998). Heritabilities of common and measure-specific components of the Big Five personality factors. Journal of Research in Personality, 32, 431-453.

Loehlin, J. C., \& Nichols, R. C. (1976). Heredity, Environment, and Personality. Austin, TX: University of Texas Press.

Lykken, D.T., McGue, M., \& Tellegen, A. (1987). Recruitment bias in twin research: the rule of two-thirds reconsidered. Behavior Genetics, 17, 343-362.

Manke, B. (1998). Genetic and environmental contributions to children's interpersonal humor. In W. Ruch (Ed.), The Sense of Humor: Exploration of a Personality Characteristic (pp. 361-384). Berlin, Germany: Walter de Gruyter.

Martin, R. A. (1996). The Situational Humor Response Questionnaire (SHRQ) and Coping Humor Scale (CHS): A decade of research findings. Humor: International Journal of Humor Research, 9, 251-272.

Martin, R.A. (2001). Humor, laughter, and physical health: Methodological issues and research findings. Psychological Bulletin, 127, 504-519.

Martin, R. A. (2007). The psychology of humor: An integrative approach. Burlington, MA: Elsevier Academic Press.

Martin, R. A., Puhlik-Doris, P., Larsen, G., Gray, J., \& Weir, K. (2003). Individual differences in uses of humor and their relation to psychological well-being: Development of the Humor Styles Questionnaire. Journal of Research in Personality, 37, 48-75.

Maslow, A.H. (1954). Motivation and personality .New York: Harper \& Row.

McGue, M., \& Bouchard, T. J. (1984). Adjustment of twin data for the effects of age and sex. Behavior Genetics, 14, 325-343.

Neale, M. C., Boker, S. M., Xie, G., \& Maes, H. H. (2006). Mx: Statistical modeling manual (7th ed.). Richmond, VA: Department of Psychiatry, Medical College of Virginia.

Nias, D. K., \& Wilson, G. D. (1977). A genetic analysis of humour preferences. In A. J. Chapman \& H. C. Foot (Eds.), It's a Funny Thing, Humour (pp. 371-373). Oxford: Pergamon Press. 
Oral, G. (2006). Creativity and humor styles in bureaucracy. Korean Journal of Thinking \&Problem Solving, 16, 83-89.

Plomin, R. (1986). Multivariate analyses and developmental behavioural genetics: Developmental change as well as continuity. Behavior Genetics, 16, 25-43.

Riemann, R., Angleitner, A, \& Strelau, J. (1997). Genetic and environmental influences on personality: A study of twins reared together using the self- and peer report NEO-FFI scales. Journal of Personality, 65, 449-475.

Rushton, J. P., Bons, T. A., Ando, J., Hur, Y. M., Irwing, P., Vernon, P. A., et al. (2009). A general factor of personality from multitrait-multimethod data and cross-national twins. Twin Research and Human Genetics, 12, 356-365.

Rushton, J. P., Bons, T. A., \& Hur, Y. M. (2008). The genetics and evolution of the general factor of personality. Journal of Research in Personality, 42, 1175-1185.

Saucier, G. \& Goldberg, L. R. (1996). Evidence for the Big Five in analyses of familiar English personality adjectives. European Journal of Personality, 10, 61-77.

Sparr, J. L., \& Sonnentag, S. (2008). Fairness perceptions of supervisor feedback, LMX, and employee well-being at work. European Journal of Work and Organizational Psychology, 17, 2008.

Thorson, J. A., Powell, F. C., Sarmany-Schuller, I., \& Hampes, W. P. (1997). Psychological health and sense of humor. Journal of Clinical Psychology, 53, 605-619.

Tortia, E. C. (2008). Worker well-being and perceived fairness: Survey-based findings from Italy. The Journal of Socio-Economics, 37, 2080-2094.

Vernon, P.A., Martin, R.A., Schermer, J.A., Cherkas, L.F., \& Spector, T.D. (2008a). Genetic and environmental contributions to humor styles: a replication study. Twin Research and Human Genetics, 11, 44-47.

Vernon, P. A., Martin, R. A., Schermer, J. A., \& Mackie, A. (2008b). A behavioral genetic investigation of humor styles and their correlations with the Big-5 personality dimensions. Personality and Individual Differences, 44, $1116-1125$.

Vernon, P. A., Villani, V. C., Shermer, J. A., Kirilovic, S., Martin, R. A., Petrides, K. V., et al. (2009). Genetic and environmental correlations between trait emotional intelligence and humor styles. Journal of Individual Differences, 30, 130-137. 
Vernon, P. A., Villani, V. C., Shermer, J. A., \& Petrides, K. V. (2008c). Phenotypic and genetic associations between the Big Five and trait emotional intelligence. Twin Research and Human Genetics, 11, 524-530.

Veselka, L., Schermer, J. A., Petrides, K. V., \& Vernon, P. A. (2009). Evidence for a heritable general factor of personality in two studies. Twin Research and Human Genetics, 12, 254-260.

Veselka, L., Schermer, J. A., Petrides, K. V.; Cherkas, L. F., Spector, T. D., \& Vernon, P.A. (2009). A general factor of personality: Evidence from the HEXACO model and a measure of trait emotional intelligence. Twin Research and Human Genetics, 12, 420424.

Wiggins, J. S. (1979). A psychological taxonomy of trait-descriptive terms: The interpersonal domain. Journal of Personality and Social Psychology, 37, 395-412.

Wilson, G. D., Rust, J., \& Kasriel, J. (1977). Genetic and family origins of humor preferences: A twin study. Psychological Reports, 41, 659-660.

Wycoff, E. B., \& Pryor, B. (2003). Cognitive processing, creativity, apprehension, and the humorous personality. North American Journal of Psychology, 5, 31-44.

\section{About The Authors:}

Livia Veselka is a PhD student in the Department of Psychology at the University of Western Ontario. Her research interests lie in the fields of behavioral genetics and personality theory. Her previous publications and conference presentations have largely addressed the theoretical structure of personality by examining existing models of personality, trait emotional intelligence, and the Dark Triad personality traits.

Address for correspondence: Livia Veselka, Department of Psychology, Westminster Hall, University of Western Ontario, London, Ontario, Canada N6A 3K7

E-mail: Iveselka@uwo.ca

Julie Aitken Schermer received her PhD in 1999. She was appointed assistant professor at Brescia University College from 2001-2003 and then assistant professor in the Management and Organizational Studies Program at The University of Western Ontario in 2003. She was promoted to her current rank of associate professor in 2006 . Her research 
areas involve all aspects of human personality, intelligence, abilities, and interests. She has published 50 articles, one textbook, and has been involved in 67 conference presentations.

Rod A. Martin completed his PhD in clinical psychology at the University of Waterloo in 1984, and has been a faculty member in the Department of Psychology at the University of Western Ontario since then. His research focuses on the conceptualization and measurement of sense of humor, and on the association between humor and psychosocial well-being. He has served as president of the International Society of Humor Studies, is on the editorial board of Humor: International Journal of Humor Research, and is the author of the book The Psychology of Humor: An Integrative Approach.

Lynn Cherkas is a research fellow at the Department of Twin Research and Genetic Epidemiology (DTR), King's College London, where she is head of the Behaviour Research Unit. Her main interest is in quantitative genetic analysis of twin data to assess the genetic and environmental influences on common complex diseases of aging and behavioral traits. Lynn has published in leading scientific journals and liaises with the media to disseminate research findings. She has a BSC in psychology from the University of Birmingham and a D.Phil. in behav iour genetics from the University of Oxford.

Tim D. Spector is a professor of genetic epidemiology at Kings College, London, and director of the Twins UK Registry at St Thomas' Hospital, London. He founded the UK Twins Registry of 11,000 twins in 1993, which is one of the largest collections of genotype and phenotype information on twins worldwide. Its breadth of research has expanded to cover a wide range of common complex traits, many of which were previously thought to be mainly due to ageing and environment. He has published over 450 research articles on common diseases and traits.

Philip A. Vernon received his PhD in 1981 and was appointed assistant professor in the Department of Psychology at the University of Western Ontario in London, Ontario, Canada in 1982. He was promoted to associate professor in 1987 and to full professor in 1992: a position he still holds. Vernon's research interests include individual differences - broadly defined - and he has published over 125 articles, 30 book chapters, and 3 edited bookson such topics as intelligence and mental abilities, normal and abnormal personality, and behavioral genetics. Vernon has served as President of the International Society for the Study of Individual Differences and is co-editor in chief of Personality and Individual Differences. He also serves on the board and as a reviewer for numerous other journals. 